Crash Under Investigation: Engaging Complications of Complicity, Coherence, and Implicature Through Critical Analysis

By: Mark P. Orbe \& Etsuko Kinefuchi

Orbe, M. P. \& Kinefuchi, E. (2008). Crash under investigation: Engaging complications of complicity, coherence, and implicature through critical analysis. Critical Studies in Media Communication, 25(2), 135-156. DOI: $10.1080 / 15295030802032275$

Made available courtesy of Taylor \& Francis: http://www.tandf.co.uk/journals/rcsm/

\begin{abstract}
****Reprinted with permission. No further reproduction is authorized without written permission from Taylor \& Francis. This version of the document is not the version of record. Figures and/or pictures may be missing from this format of the document. $* * *$
\end{abstract}

\begin{abstract}
:
Using a critical analytic lens, this essay examines how race, racism, and race relations depicted in the movie Crash reflect complicity, coherence, and implicature. The essay first utilizes complicity theory to offer a critical analysis of the film, then provides a thematic analysis of student reactions to the film as a means of gaining insight into multiple possible readings of the film. The analysis demonstrates how a simultaneous, multilayered experience of complicity, coherence, and implicature functions as a process of mediation for the viewing audience.
\end{abstract}

Keywords: Complicity; Coherence; Implicature; Crash; Race Relations

\title{
Article:
}

Historically, film has played a significant role in how the U.S. public has come to understand racial prejudice, discrimination, and racism. In fact, Patton (1995), in her analysis of early "race" films like The Birth of a Nation and Pinky, explores the ways in which government censorship was enacted to monitor and "protect" against the potential race riots that it was feared would result from volatile content. Over the years, Hollywood has paid significant attention to race relations in the postbellum South, producing such films as Rosewood, Mississippi Burning, A Time to Kill, and A Long Walk Home. Some scholars (Gabriel, 1998) suggest that such movies forced European Americans to confront the reality of racial hate, injustice, and brutality. However, a small, but significant, body of research has criticized the ways in which these films represent issues of race, racism, and race relations, focusing on interracial cooperation and deemphasizing social inequalities between different racial groups (e.g., Cuomo, 1995; Miller \& Rode, 1995). Such research demonstrates that these films highlighted the superiority of European American heroes and marginalized African American agency (Madison, 1999).

Interestingly, race relations have been a pertinent and profitable topic in Hollywood's movies (Detweiler, 2005). While such films as Do the Right Thing, Boyz in the Hood, and Grand Canyon have experienced commercial success, the underlying theme of race also appears to resonate with the Academy Awards community (Kotler, 2005). Vintage films such as In the Heat of the Night and Guess Who's Coming to Dinner, as well as more contemporary examples such as Driving Miss Daisy and Monster's Ball, have received accolades. However, interest in such movies - especially those located in Los Angeles - appeared to vanish following the 1992 racial uprisings. Then, in the summer of 2005, Crash was released. According to one critic (Sicinski, 2005), it was "one of the best-reviewed films of 2005" (p. 51), while Roger Ebert flatly stated that no film "portrays the complexities of race relations in America any better" (quoted in Atkinson, 2005, p. 20).

Distributed by Lionsgate, a Canada-based independent studio, Crash is a small independent movie that cost a mere \$6.5 million to make. Movie reviews praised the efforts of the film's writer/producer/director, Paul Haggis, and described the movie as an "intelligent ensemble piece" (Kermode, 2005, p. 33) with multidimensional, engaging characters that represent the complexity of humanity (McCormick, 2005). Other critics described it as "hyper-articulate and often breathtakingly intelligent and always brazenly alive" 
(Schwarzbaum, 2005, p. 65). People Weekly stated, “[F]ew films make you care this much” (Rozen, 2005, p. 39) and added:

Here comes a direct order. See Crash. Movies don't come better acted, as luckily written, or most importantly, more capable to growing a viewer emotionally and intellectually than this exceptional drama about race and ethnic relations in urban America today. (p. 39)

Despite a significant amount of praise, Crash appeared to provoke and polarize other critics (Kotler, 2005). Reviews described the portrayal of multiracial characters as having "a racial-quota, show-of-hands presence" (Sicinski, 2005, p. 52) within a story line which was best characterized as "the mother of all web-of-coincidence films" (Atkinson, 2005, p. 20). As such, the "film's mix of paranoia and pseudo- redemption is too inflated to be convincing" and reliance on "such violent contradictions limited its ability to explore character development" (Cunneen, 2006, p. 14). According to some observers, the "contrivance-laden 'analysis' of race relations" (Sicinski, 2005, p. 51), serving as a platform for sociopolitical debates (Kotler, 2005), was frustrating because it promoted the myth of human connectivity despite social divisions (Detweiler, 2005).

With little media fanfare, Crash demonstrated surprising resilience, drawing consistent audiences throughout the summer of 2005 and ultimately generating more than $\$ 55$ million in ticket receipts (Kotler, 2005). The film regained momentum following increased national exposure after Oprah Winfrey's self-described "Crash moment" inspired a show dedicated to the movie; when the DVD was released in September 2005, it soared to the top of the sales chart (Thompson, 2005). With increased visibility and multiple awards-including the Oscar for Best Picture- Crash has prompted many to ask a number of questions, including: Are U.S. race relations as bad as the film makes them out to be? Is the film a realistic depiction of social life or a mass-mediated manipulation? And how might the film impact viewers in terms of their own understanding of race in contemporary U.S. society (Cunneen, 2006)? Drawing from a considerable foundation of existing scholarship that critically explores issues of race within feature films (e.g., Bourgeois, 1992; Bowers, 1994; Chidester, Campbell, \& Bell, 2006; Rowland \& Strain, 1994), we seek to extend this body of work through a critical analytic examination of Crash. In particular, we explore one question: How does implicature serve as a process of mediation for the viewing audience? By implicature, we refer to the idea that all human beings are interrelated and interdependent - a core concept in Mark L. McPhail's (2002) complicity theory. Implicature is at the heart of our critical reading of Crash, as well as our analysis of viewer responses to the film.

Consequently, we turn now to a description McPhail's complicity theory.

\section{Complicity Theory}

Complicity theory (McPhail, 1994a, 1998a, 2002) has been used by various communication scholars to critique existing representations of race. This has included critiques of movies by Spike Lee (McPhail, 1996a), speeches by Louis Farrakhan (McPhail, 1998b), and interactions on U.S. college campuses (Patton, 2004), all of which have been described as grounded in complicity. Other scholars have pointed to complicity theory as a helpful framework for transforming the current state of race relations into more liberating dialogues (Jackson, 2000) where true racial reconciliation can occur (Hatch, 2003). The framework appears especially fitting for our analysis as it was created specifically to study issues of race, language, and communication (Allen, 2007), and challenges our basic understanding of race and how we experience racial differences.

Complicity theory is grounded in two key ideas. First, at the core of racism is a language system that divides and ranks human beings in terms of "black" and "white" (McPhail, 1994a). According to McPhail (1991), these terms participate in a "language of negative difference" (p. 2) that affects social reality. In other words, racism and the concept of race are interrelated; in order to challenge racism you must challenge the language that we use regarding race. Importantly, racial designations are made and maintained with little recognition of our commonality and interdependence (Hatch, 2003), resulting in social practices that perpetuate the principle of negative difference in human interaction (McPhail, 1991). Hence, racism is not merely a problem of "Blacks" and "Whites," it is a consequence of constituting the world through a raced discourse (McPhail, 2002). 
The second idea central to complicity theory is that dominance and marginality are not fixed (McPhail, 1996b). The theory challenges the idea that racism is a social practice of domination that can be reduced to a "relationship between oppressors and the oppressed, between victimizers and victims, between white people with power and black people without it" (McPhail, 1996b, p. viii). According to complicity theory, racism reflects the Western predisposition to produce essentialist classifications and categories - separate, distinct, general groups (McPhail, 1994b). What this essentialism fails to take into consideration is how race exists within a social system that also marginalizes people based on gender, class, age, and sexual orientation (McPhail, 1994b). Acknowledging this complexity helps individuals to recognize how positions of dominance and marginality are multidimensional. In this regard, complicity theory advocates for efforts that avoid overgeneralizations based on a single social location.

As a means to advance the ideas central to complicity theory, McPhail introduces three key concepts: complicity, coherence, and implicature.

Complicity means “an agreement to disagree” (McPhail, 1991, p. 2). In the context of McPhail's work, complicity involves using language that highlights differences instead of commonalities and emphasizes division at the expense of unity (McPhail, 1994b). In addition, complicity occurs when individuals fail to resist discourse that privileges some groups over others (Fine, 1991). According to complicity theory, productive race relations can never occur when complicity is the norm. Instead, we must move from complicity to coherence.

Coherence is a concept that emphasizes interconnectedness and commonality in discursive attempts to facilitate harmonic relations (McPhail, 2002). It avoids a focus on negative differences and critiques existing frameworks that depict human beings in terms of separate and distinct races (McPhail, 1998a). While complicity hinges on the idea of negative difference as oppositional force, coherence sees differences as complementary (McPhail, 1996b). Accordingly, coherence defines and constructs reality in a way that does not privilege one position at the expense of another (McPhail, 1991). As such, it challenges the status quo on which racism functions (Patton, 2004).

Finally, implicature involves a basic acceptance of the belief that we are all implicated in each others' lives (McPhail, 2002). Implicature is more than having empathy for others; it includes the idea that human beings are "linguistically, materially, psychologically, and spiritually interrelated and interdependent" (Dace \& McPhail, 2002). In other words, implicature is grounded in the idea that we are all connected; what affects one of us affects all of us.

The remainder of this essay will explore the ways in which Crash signifies race, racism, and race relations in contemporary U.S. culture. First, we offer a textual analysis of how Crash features images that reflect complicity, coherence, and implicature within a larger racialized society. Then, like the methodological approach utilized by Watts and Orbe (2002), we facilitate a thematic analysis of student reactions to the film as a means of gaining further insight into the multiple possible readings of the text.

\section{Critical Analytic Analysis of Crash}

\section{Examining Crash as Cultural Text}

\section{Implicature as core plot}

Crash follows the complex and unexpected ways in which strangers from diverse backgrounds interact with each other in Los Angeles over a 36-hour period. The movie begins with a car accident in which two police detectives, Graham and his Latina girlfriend Rita, are involved on their way to investigate a murder case. In the background, Graham mutters: "In L.A. ... We Crash into each other so we can feel something." This utterance sets the backdrop for the rest of the film. Crash follows a series of collisions-based on race/ethnicity, culture, class, and/or gender - that occur in Los Angeles over the course of two days prior to the accident. The collisions involve an ensemble of individuals whose individual storylines, over time, become intertwined. 
One storyline focuses on Graham's professional and personal life as an African American man. His life is complicated by a mother struggling with drug addiction and a younger brother, Peter, engaging in criminal activities with his friend Anthony. A second storyline revolves around Rick, a European American district attorney, and his constantly disgruntled wife, Jean. Early in the film Rick and Jean are carjacked, at gun point, by Anthony and Peter. Yet another storyline focuses on the working relationship between two European American police officers, Hansen and Ryan. Prompted by a search for Rick and Jean's stolen SUV, the officers stop, harass, and demean Cameron and Christine, an African American couple. Cameron is a successful television director who has made many compromises to succeed in white-dominated Hollywood. During the stop, his wife Christine suffers a humiliating sexual assault at the hands of Ryan. As the film progresses, two other families' lives become central to this labyrinthine plot. The first family is headed by a Persian storeowner, Farhad, who buys a gun to protect his business. The second family is headed by a Mexican American man, Daniel, whose profession as a locksmith brings him into contact with Rick and Jean, and Farhad and his wife. Crash tells the story of intertwining narratives that culminate in a series of "collisions" between these characters.

The film begins with a series of separate scenes that introduce viewers to the characters. However, not much time elapses before the connectedness between these diverse characters becomes apparent. Initially, the connections between characters appear coincidental and secondary to the plot. However, as the film progresses, viewers witness how persons' lives are interconnected in multiple and meaningful ways. Thus, the core lesson of Crash's plot is simple: We are all implicated, explicitly and implicitly, in each other's lives. The implicature throughout the film is so strong, in fact, that it became a point of critique for some reviewers who underscored the premise "that we are connected to each other, like it or not" (Detweiler, 2005, p. 46.).

According to Dace and McPhail (2002), implicature exists materially, sociologically, and psychologically. The connectedness of diverse people living in the greater Los Angeles metropolitan area is demonstrated through physical and material interdependence. Multiple examples illustrate the degree to which the film emphasizes the notion of physical implicature. For example, Peter is directly connected to most of the characters in the film, albeit in divergent ways. His brother Graham is a LAPD detective; Peter and his "partner in crime" Anthony carjack Rick and Jean, who later promote Graham after he makes a deal to help abolish Peter's criminal record. Peter and Anthony accidentally hit with their SUV an Asian American man who happens to be married to an Asian American woman involved in the car accident with Graham and Rita at the beginning of the film. Later in the film, Peter and Anthony attempt to carjack Cameron. In the end, Peter is murdered by Officer Hansen, who was involved in the racist traffic stop of Cameron and Christine; earlier officer Hansen helps to diffuse a potentially deadly confrontation between Cameron and other police officers. Graham, his mother, and Rita meet in the hospital to identify Peter's body; we discover that the doctor on duty is Farhad's daughter. Earlier in the film, Farhad mistakenly blames Daniel, the locksmith, for the loss of his business and attempts to shoot him with the gun he has purchased.

For individuals who have seen the movie, this complex, multi-layered description of one character's travels should make sense; however, for those unfamiliar with the film, it may be difficult to follow. In fact, all of the physical examples of implicature demonstrated throughout the film may only become apparent after multiple viewings. The same may be said of the ways in which the film illustrates psychological implicature, albeit in less explicit ways. For example, the film depicts a nearly universal longing for "home" within several storylines. Idealistic conceptualizations of home conjure up images of safety, acceptance, unconditional love, and security; these facets represent common points of value for all humans. Throughout the film, viewers are reminded of the value of home and the important role that it plays in our lives. In one storyline, Graham's mother pleads with him to find Peter, when there is a search warrant out for his arrest: "[T]ell him I said to come home." Later in the film, we witness how Peter attempts to make it back home only to be murdered after accepting a ride from Hansen. In contrast, Cameron appears to be on the edge of losing his life during a volatile confrontation with the police, an event brought on by professional and marital stress (Matthews, 2005/2006). Despite Cameron's hostility toward the LAPD, when Officer Hansen tells him, "Go home," he says: "Yeah that I can do.' Before arriving home, however, he parks and contemplates his life; his cell phone rings and reads: 
Home calling ... As he answers the call to reconnect with home, we recognize that his foundation, as well as his future, remains intact. Such was also the case for Rick, who answered a similar call from his distressed wife in spite of being preoccupied with another woman. ${ }^{2}$ In the closing montage, viewers see two men-Daniel and Rick - standing in their homes gazing out of their windows as their families sleep. The film suggests psychological implicature across diverse people by meditating on the importance of each of their homes. ${ }^{3}$ As described within this section, a sense of implicature is at the core of Crash. Through both physical and psychological means, the characters in the film are connected in substantial ways. While this remains explicitly clear for viewers, what remains unclear is whether the characters themselves recognize the multiple ways in which their lives are implicated with one another.

Defining race relations through complicity

Crash presents a powerful picture of how complicity can negatively affect interracial interactions. We need not go beyond the first seven scenes in order to demonstrate this complicity. Specifically, these scenes feature a "language of negative difference" which extends beyond simple white-black binaries. In the first scene, a minor car accident provides the context for a heated interaction between an Asian American woman and Rita; their argument features the use of racial stereotypes about Asian dialect and Hispanic driving habits. The very next scene continues to highlight the blatant ways in which interracial interactions are defined in complicity. The characters and context are different, yet, as the conversation below illustrates, the conflict is shaped by racial divisions based on misunderstanding, disrespect, and mistrust. In a gun shop, Farhad and his daughter stand in front of a counter facing the European American store owner. The owner asks Farhad what kind of ammunition he wants. Farhad asks his daughter in Farsi what the owner said, and they converse briefly in their native language. The owner grows irritated and interrupts the conversation:

Owner:Yo, Osama! Plan a jihad on your own time. What do you what?

Farhad:Are you making insult at me?

Owner:Am I making insult "at" you? Is that the closest you can come to

English?

Farhad:Yes, I speak English. I am American citizen.

Owner:Oh, God, here we go.

Farhad:I have right like you. I have right to buy gun.

Owner:Not in my store, you don't! Andy, get him outta here now!

Daughter: Go wait in the car.

Owner:Now, get out!

Farhad:You're an ignorant man!

Owner:Yeah, I'm ignorant? You've liberating my country. And I'm flying 747s

into your mud huts and incinerating your friends? Get the fuck out! Farhad:No, you get the fuck out!

While this scene reflects the complicitous nature of post-September 11 race relations, the third and fourth scenes highlight complicity in terms of white-black differences. The third scene begins with a discussion between Peter and Anthony, who describe how European Americans typically view black men; the scene ends when these black men carjack Rick and Jean. The fourth scene, which portrays an instance of road rage that turns deadly, immediately becomes racialized when Graham says of the shooter that this "Barry Gibb looking cop killed the wrong nigga this time."

These first four scenes set the stage, as regards the current state of race relations in LA; diverse individuals live in close proximity to one another but remain segregated - which contributes to a heightened sense of complicity. The fifth scene occurs in the luxurious home of Rick and Jean. The conversation revolves around how Rick will provide the "damage control" necessary to reduce the potential negative effects on his re-election campaign; after all, African Americans make up a 
key voting block for him. In addition, racial and ethnic fear and distrust are magnified in the scene when Jean calls Daniel, their locksmith, a "gang-banger":

Jean: I would like the locks changed again in the morning. And you know what, you might mention that next time we'd appreciate it if they didn't send a gang member ...

Rick: A gang member?

Jean: Yes, yes.

Rick: What do you mean? That kid in there?

Jean: Yes. The guy in there with the shaved head, the pants around his ass, the prison tattoos.

Rick: Those are not prison tattoos.

Jean: [Interrupting] Oh really? And he's not gonna go sell our key to one of his gang banger friends the moment he is out our door?

Rick: You've had a really tough night. I think it would be best if you just went upstairs right now and ...

Jean: [Interrupting] And what? Wait for them to break in? [Yelling] I just had a gun pointed in my face!

Rick: [Agitated] You lower your voice!

Jean: [Yelling] ... and it was my fault because I knew it was gonna happen. But if a white person sees two black men walking towards her and she turns and walks in the other direction, she's a racist, right? Well I got scared and I didn't say anything and ten seconds later I had a [jabbing her finger into Rick's chest] gun in my face. Now I am telling you, your amigo in there is gonna sell our key to one of his homies and this time it'd be really fucking great if you acted like you actually gave a shit!

Racial difference also becomes a salient issue in a conflict between Officer Ryan and an African American health care administrator, who refuses to appeal against an HMO-sanctioned limitation on his father's treatment. The police officer's anger over the institutional power that the woman has in terms of his father's health appears to trigger his need to exert his "legitimate" power as a police officer. His resentment provokes the instance of "Driving While Black"- arguably the most emotionally charged scene in the film-where Cameron and Christine are humiliated and subjected to personal, racial, and sexual intimidation. ${ }^{4}$

In short, these initial scenes situate complicity at the core of race relations. With great efficiency, Crash represents the complicitous nature of race relations through depictions of various racial/ethnic groupsLatino/as, African Americans, European Americans, and Asian Americans. In some scenes, like when a white executive producer demands that Cameron re-shoot a scene in a television show where an African American actor does not "sound black enough," interracial complicity takes center stage. However, midway through the film, we are moved from complicity toward greater coherence.

Beyond complicity toward coherence

A key turning point in the film occurs immediately following the scene in which Officer Ryan fondles Christine while Cameron painfully watches and Officer Hansen stands in neutral support of his actions. Following this gut-wrenching scene, Crash begins the process of moving from complicity to coherence. Consider, for example, the next five scenes (Scenes 8-12); each serves as an important point of character development that allows viewers to understand individuals beyond their racial identity. Scene 8 provides information that allows the viewer to understand that Farhad was purchasing a gun as a result of his wife being robbed. In Scene 9, we witness the painful ways in which Cameron and Christine, in terms of their gender identities, cope with the police officer's actions; through this interaction, we get a glimpse of how racism impacts people of color of all socio-economic statuses. Scene 10 defines Daniel Ruiz not as a former "gang-banger" but as a loving father who works around the clock in order to make enough money to move his family — including his daughter who had a bullet come through her window - to a safer neighborhood. ${ }^{5}$ Through a humorous exchange about oppression, language, and music, the next scene encourages viewers to recognize the humanity of Peter and 
Anthony. Despite being criminals, they refuse to leave the Asian American man to die on the street after striking him with their vehicle. Scene 12 demonstrates the humanity and social consciousness of Officer Hansen. Refusing to condone the racist actions of his partner, he unofficially brings the issue to the attention of his supervisor. While Officer Hansen does not confront his partner's behaviors directly, he allows viewers to understand that many white men are not racist.

As Crash progresses, events begin to unfold that demonstrate the interconnectedness of various characters. Through different interactions, viewers come to understand the power of implicature. In less subtle ways, they witness the difficult ways in which all individuals of all racial and ethnic backgrounds negotiate both complicity and coherence. This negotiation is apparent in several scenes that depict the complex ways in which characters oscillate between uniting through human connectedness and (mis)understanding through racial difference. Take, for example, the scene in which Graham and Rita are making love. During this intimate moment the phone rings; Graham answers it and tells his mother: "I can't talk now, I'm sleeping with a white woman." In the argument that follows, Graham explains to Rita that he meant to anger his mother by calling her a white woman, but the scene also suggests that some blacks have an essentializing view of Latinos. As such, Graham's actions move the moment of intimate connection to one of racial misunderstanding.

In Scene 27, the complex negotiation between complicity and coherence begins to get more intense. In this scene, Officer Ryan approaches Officer Hansen to discuss their separation as partners; Ryan tells Hansen: "You think you know who you are? You have no idea." The indication of an unstable identity sets the stage for the last 15 scenes, which work to complete the film's movement from complicity to coherence. Through several different subplots, viewers are taken on an emotional rollercoaster, involving multiple life and death situations which hinge on the characters' ability to work effectively through complicity to understand the "Other" through coherence. For example, the scene where Officer Ryan rescues Christine from a wrecked car powerfully illustrates this movement. In this scene, Officer Ryan squeezes himself into an upside-down wrecked car to rescue Christine. She turns her head to face the police officer and realizes that he was the cop who sexually molested her the previous night:

Christine: [Hysterically] Don’t touch me! Don’t touch me! Keep away from me!

Ryan:Lady, I'm tryin', I'm tryin' to help you.

Christine: Fuck you! Not you! Somebody. Anybody else! Please, somebody! Not you!

Ryan: Stop moving!

Christine: Not you! No! Get your filthy fucking hands off me!

Ryan:[In a raised voice] Stop moving, Lady. I'm not gonna fucking hurt you!

[They look at each other in silence for seconds]

Ryan: Okay. Okay.

Christine: [Crying] Please don't touch me. Don't. Don't.

Ryan:I'm not gonna touch you. But there's nobody else here yet, and that's

gasoline there. We need to get you outta here right away, okay?

Christine: Oh, my ... oh, my ... oh, my god, oh my god.

Ryan:Okay. I need to reach across your lap. Can I do that, please?

Christine: Yeah. Yeah.

Ryan:Thanks. [He reaches his arm first to straighten her skirt so her exposed thighs are covered] Is anything broken?

Christine: I don't think so. [Their faces are almost touching as they have this talk] [Sobbing] Are you gonna get me out?

Ryan:Yeah, I'm gonna get you out, okay? Look at me, look at me. I'm gonna get you out. [He can't release the seatbelt from her body and grunts] Oh, fuck! I'm sorry.

Christine: That's okay.

Ryan:I'm gonna have to cut your belt, okay? 
In this scene, coherence is at the heart of a meaningful, potentially life-changing interaction. Coherence can be seen in other interactions also: when Cameron and Officer Hansen negotiate a peaceful outcome to a potentially deadly stand-off, and when Daniel Ruiz's daughter "saves"' her father who was without his "protective cloak.' 6 Farhad's daughter purchased blanks for his gun without him knowing. Thus, when Daniel's daughter leaps to his rescue and Farhad's gun goes off without harm to Daniel, Farhad sees her as an "angel" and his vengeful lust is dissolved. Unfortunately, in another scene, we witness exactly what can happen when an individual cannot overcome the complicitous nature of his racial perceptions: the (good, anti-racist) police officer, Hansen, cannot fathom that he has anything in common with Peter, who he picks up hitchhiking, and mistakenly murders him.

As Crash comes to an end, characters reflect on the important lesson of the film: We are all connected in one another's lives, the film tells us, and in order to survive we must practice coherence. The film ends with several moving scenes that vividly illustrate the powerful ways in which common struggles speak to the core of human existence and connection. As such, it is difficult not to recognize the coherence as characters reflect on how events over the course of a 36-hour period come to symbolize negotiations of fear, love, anger, humility, belonging, respect, success, safety, identity, and ultimately hope. At this point, the film resists defining people's experiences in terms of essentialized racial and ethnic categories; instead, common human experiences are emphasized. As Madison (1995) describes, viewers find it difficult to resist being engaged in such media representations:

At one level, we temporarily suspend or displace a very real awareness of racial difference for a universal consciousness of sorts in order at least to have the experience. We know these characters don't look like us; we may even know that if they did, the story could not exist. But we are engaged, because there are moments when passion and yearnings transcend race distinctions, and we empathize with those human feelings. (p. 226)

As such, implicature can function as a process of mediation between complicity and coherence. Media texts such as Crash intervene in the social lives of viewers and provoke them to recognize implicature. In this regard, the viewing experience is not passive; instead it brings to life instances of how implicature may be manifested in everyday social relations. We explore this idea further through an analysis of audience reactions to Crash.

\section{Analyzing Audience Reactions to Crash}

In the previous section, we provided a critical analysis of Crash. In particular, we focused on how the film reflects divergent representations of race and interracial relations that, through implicature, moved from complicity to coherence. Since films are powerful means by which individuals understand their identity, lives, and relationships (Brummett, 1985; Giroux, 2002; hooks, 1996; Young, 2000), it is important that we turn our attention to viewers. Accordingly, we conducted a qualitative study to see how viewers' reactions to Crash may reveal complicity, coherence, and implicature in their everyday lives.

\section{Methodological Framework}

We collected and analyzed written descriptions of student responses to Crash. The start of our data collection coincided with the limited release of the film in June, 2005. At that time, the first author was teaching an upperlevel undergraduate course on interracial communication. At the urging of several students, the class organized a viewing and discussion of the film. In addition, students were given the opportunity to write an extra credit paper describing their reactions to Crash. Over the course of 18 months (June 2005 October 2006), 136 students provided written descriptions of their perceptions of, and reactions to, Crash.

Student reactions were collected in nine different communication classes (three intercultural communication classes, three interracial communication classes, and three interpersonal communication classes) at three different college campuses (one large state university and one mid-sized community college in the upper Midwest, and one mid-sized regional university in the southeast). ${ }^{7}$ In all of the intercultural and interpersonal classes, students were given the opportunity to complete an assignment, two to three pages long, for extra credit; this was more or less a free essay in which students were asked to assess whether they found the movie 
powerful, and provide reasons for their answers by using various communication concepts. In the interracial communication classes, the student reactions were obtained via a course assignment, as the first of three required papers. Students were required to submit a paper two to three pages in length, in response to: "Describe your racial standpoint and share your 'gut reaction' to Crash." 8 All responses were type-written and doublespaced, resulting in a total of 395 pages of text.

Following the collection of student reactions, we conducted a thematic analysis. Based on the work of Owen (1984), we utilized three criteria - repetition, recurrence, and forcefulness - to assist in the emergence of themes (see also Apker, Propp, \& Ford, 2005). Consistent with the work of Wright and Orbe (2003), we each conducted an individual analysis of the data by searching for frequent appearances of particular words and phrases (repetition). At this stage, potential themes regarding emotions, tensions, misunderstandings, and perceptions of the film were identified. Second, both authors made notes regarding how common meanings were communicated via various articulations (recurrence). These preliminary analyses were then used to generate thematic insight into the complexities of how students were engaged by the film. Throughout this process, we avoided attempts to categorize and count student reactions; instead we utilized Owen's third criterion, forcefulness, to identify thematic insights that were important to consider despite not appearing consistently across the text. In this regard, we took note of how certain excerpts were emphasized, by different codes (e.g., ALL CAPS), punctuation (e.g.,!!!! or???), or format (e.g., bold or italics), that situated them as powerful points of insight to be incorporated into our analysis. Following a review of the preliminary themes generated from our individual analyses, we collectively re-examined the text to see how the emergent themes responded to the notions of complicity, coherence, and implicature. As the analysis below shows, the reactions to Crash revealed the presence of those three concepts in complex ways.

\section{Enhancing Critical Analysis through Qualitative Thematization}

\section{Negotiations of explicit complicity}

Complicity is achieved through discourse that promotes negative views of difference (McPhail, 1994b, 1996b, 2002). As a European American student in the southeast observed, "[W] focus on the differences rather than seeing all of the similarities we share," and those differences are often construed as the source of racial problems. Several students articulated that one of the main messages of the film was ever- present racial antagonism, hatred, and injustice. For example, a European American female student in the southeast wrote: "Regardless of what we learn from the movie or life in general, stereotypes, discrimination, and the abuse of power will always exist. The movie showed this never ending cycle by starting and ending with [a] Crash." Similarly, referring to racism, a student from the Midwest wrote: "[T]here is nothing we can do as a society to really change people's mind[s]." Although the authors of those comments did not themselves express any negative views of differences, they clearly defined the world as being plagued by perpetual divisions and animosity and concluded that this reality will never change. For them, Crash served as a gloomy reminder of this hopelessness. These authors essentialize hopeless aversion and remain disengaged, and, thus, participate in complicity.

Such feelings of hopelessness are in contrast to other essays whose tone represented the possibility of change. For example, a female Indian American student from the southeast reflected:

The movie kind of begins with a Crash and ends with a Crash, signifying that there will be the same issues everyday for people to deal with. However, there is something different this time. There is an opportunity to think different[ly] and be optimistic. I was left with the feeling that there are a lot of things in this world that are not under control. But there are things that are in our control. You may not be able to stop what is happening, but you can control how you react. It reminded me of the saying, if you don't like the way the world is, you change it. You have an obligation to change it. You just do it one step at a time.

Other authors similarly wrote that Crash brought them face to face with racism and provided them with opportunities for "thinking ways to change my own actions," and "opened the door for discussion." These students acknowledged that racism and prejudices are hard to overcome, but they also stressed that there are some things they can do to improve the situation. In this regard, students appeared to negotiate the complicity represented in the film by becoming motivated by it. 
Negotiation of complicity was also evident in students' comments made with regard to the realness of the race relations depicted in Crash. Moreover, those comments notably reflected racial standpoints. Without exception, students of color described the film as realistic; many shared in their essays that the scenarios in the film were very familiar to them. African Americans and Latino/as were especially forthcoming in their descriptions of the parallels they saw between the film and their lived realities. This was expressed in terms such as, "[I]t is almost daily that I or someone I know experience this type of discrimination," and, "I felt like I was in the movie."

In contrast, the reactions of European American students were somewhat divided. On the one hand, there were many students who thought that the film represented reality well. A male student from the southeast, for instance, wrote that Crash was "the only movie that is not afraid to tackle the themes of race and ethnical tension in today's American society." For those students, the film served as a catalyst for critical reflection about society. A number of students also endorsed the depictions of race relations in Crash by noting that the film compelled them to examine their own prejudices. For example, a female student from the Midwest observed:

[Crash was the] most life changing film I have ever watched. I was challenged and uncomfortable and I hated that I recognized many aspects of myself in several different characters .... I could see through the characters, the private racist thoughts that I would never admit to thinking, but of course I do.

On the other hand, a significant number of white students felt that the film exaggerated reality. They described the film as being "a little over the top," "harsh," and "unrealistic" and therefore, "[C]ommon citizen[s] cannot relate it to anything they have experienced or witnessed." A student from the southeast expressed her dislike of the film in light of the exaggerated depictions of race relations:

Personally, I didn't like the movie Crash. I went to the movies to see it when it came out, and it is the only movie that I have ever walked out of.... Although it was obviously trying to point out the racism that exists in our society today and how wrong it is. It was just too depressing for me. It was also so extreme. I know that racism definitely exists, but I'm not convinced that it is as extreme as Crash tried to make it out to be.

To the extent that those and similar comments were made only by white students, they appear to reflect dominant racial locations held by whites in the U.S. That is, white privilege allows these observers to deny the influence racism has on the everyday lives of people of color. Other white respondents, although not in denial, responded to the racial conflicts shown in the film with expressions such as "hard to imagine," "amazing," "cannot believe," and "had never thought about." McPhail (2004) describes those uniquely white responses as "a certain kind of blindness, a dialogic deafness, a discursive dumbness; see no evil, hear no evil, speak no evil" (p. 398). Complicity is thus not only maintained through negative difference but also through blindness and denial (McPhail, 1996b, 2004). When we fail to engage the reality of racism, we participate in complicity.

As discussed above, some students' reactions to Crash point out that the film may be read as a testimony to relentless racial antagonism or as exaggerated and unrealistic portrayals of racial inequality to be dismissed. In sharp contrast to those readings, a large number of students, as will be shown in the next section, felt that the film was not only realistic but also that it helped them to realize similarities that people share and influences that people have on others' lives.

\section{Coherence through commonalties and implicature}

Coherence as both an ontological and epistemological worldview pays attention to the commonality and interconnectedness of human experience (McPhail, 2002). In the student papers examined here, the theme of commonality was recurrent and was discussed on several different levels and with various foci. Most pervasively, commonality was stressed in terms of traits that humans share regardless of racial and cultural background. First, a number of participants expressed their support for the film's depiction of characters as complex individuals who are capable of being both "good and bad." While the dominant socialization, including the media, often encourages binarism and polarization, the participants found Crash to be an 
exception to this tendency and felt that the film was "real" in its portrayal of human nature. One white female's words represent this point:

Most movies depict characters as good or evil, strong or weak. This portrayal sends a message that we can define people and that doing a bad deed makes you inherently bad. As most know, this is simply not the nature of humanity. Crash did an excellent job showing the diversity of human action. Nearly every character in Crash was depicted as a well-rounded character with positive attributes as well as flaws. It was a powerful lesson in forgiveness, tolerance and acceptance; not only of others, but of myself.

This individual, along with many others, was drawn to the film for its ability to convey humanity as something intricate and multifaceted. The characters' complexity, shown in their "both/and" depiction, is central to a dialogic understanding of the Other (McPhail, 1996b). Several respondents noted that, unlike most other films, Crash represented "multiple viewpoints and cultures," which they agreed is critical to the understanding of other perspectives and "fostering conversations with each other." Collectively, those reflections indicate that, in order to move from complicity to coherence, binarism must be abandoned and divergent standpoints must be brought together.

Commonality was also discussed in terms of the emotions that people share no matter how different their backgrounds may be. Many students stressed how we all feel similar intense emotions in certain circumstances. This ability to relate to the humanity of all characters was a frequent source of comments, including this from one Midwestern European American woman:

The characters were so versatile because no matter what background the character was from you could see yourself in their shoes. Even if the character was a black male, I as a white female had been in their shoes at least once in my life. This provides us with a powerful thought that we are all similar.

One of the scenes most cited for illustrating shared emotional experiences involved Daniel Ruiz's daughter stepping out in front of her father to protect him when Farhad attempted to shoot Daniel. One student, a white male from the southeast, articulated the common, intense emotional reactions the scene evoked:

There are things that transcend violence and negative emotions. When the young Hispanic girl Laura was shot it affected everyone. It affected the family of course, but it also affected the man who wanted to shoot the locksmith. The Persian man was filled with such hate that he wanted to harm someone who he thought was to blame for his problems .... When a child is in danger or is hurt amidst the fighting and the hate it makes people notice. Children are innocent and should not have to suffer for the problems of other people. We see children of any race as innocent. Why is it that we cannot see the adults as innocent as well?

Other students referred to the scene in which Christine was sexually assaulted by Officer Ryan. Female students expressed their identification with the character on the basis of gender. For example, a student from the southeast wrote: "Although I am a white woman, I understand as a woman when the African American woman was harassed. I felt anger, sadness, humiliation, and disgust at the same time." Spotlighting the existence of a universal morality (e.g., children are innocent and should not be harmed) or common gendered experience within a patriarchal society, many students spoke to the importance of paying attention to "similarity in difference" (McPhail, 1996b, p. 79). For them, the film showed that similarities exist between groups despite the prevailing practice of viewing difference and the other as vile, opposition, and anomaly.

Along with commonalities, interconnectedness was frequently stressed by the students as a powerful theme in Crash. A white male from the Midwest commented: "You cannot simply watch this movie. You feel for the characters and begin to feel your own implication in the racist society that the movie portrays.' Many othersregardless of racial background - spoke of this theme, noting that we "influence one another regardless of how many degrees separated we are," "for better or worse" because everyone "is connected in some way." Consequently, "[A] person can influence or change someone else's life without even knowing it." This realization of implicature can be overwhelming. A white female student in the southeast articulated this point: 
My biggest take away from the film was the interconnectedness of it all. The ways that we can touch each others lives are infinite, and the sheer power that we have to make a change in someone's life is intimidating. How we choose to use that power is up to us, and hopefully we do the right thing.

For some students, having such power meant becoming thoughtful in the way they relate to the Other, as stressed by a young African American woman in the southeast: "I learned from the movie that no matter what is going on in my life, it is important to consider what could be going on in someone else's life that I may interact with." In this reflection, the Other is no longer someone who is separate and oppositional but someone to be cared for and understood. The Other is now someone who shares the same humanity. A student's words sum up this idea: "The one thing that I remember above all of the other issues and conflicts shown in this movie is that, deep down, everyone has a need to be loved, to love others, to connect and to do good."

\section{Negative similarities: Complicity within coherence?}

Coherence is achieved through recognizing and honoring similarities in humanity (McPhail, 1994a,b, 1996b). Similarities are, however, not always about positives. Quite a few students pointed out negative traits that we all share, regardless of racial and cultural background, as a dominant theme of Crash. This observation was expressed in comments such as: "[W]e all carry around racial baggage"; "[T]o some extent we are all racist"; and "[E]ven when you think you don't have any racist tendencies or bias toward races, in all actuality we all do." The negative similarities may serve as a way to bring people closer to each other when recognized as an opportunity for self-reflexivity. For example, a European American student wrote that the movie "forces every person to take a look in the mirror and think how they can possibly better themselves."

Negative similarities in the film, however, can also serve to fuel distrust of the Other. Instead of seeing the potential good in everyone, or even the potential for both good and bad, some students focused on the undeniable negativity present in all. One European American man from the Midwest, for example, asserted: "In the end, everyone is a bad guy .... People in the world do not trust enough but I can see why, because there has been a lot of reason not to." From the perspective of some well- intentioned white students, such a realization also works to make the historical institutionalized power wherein racism is situated nonexistent in today's society. In the end, racism is experienced equally by all, as this European American young women wrote:

I find it very interesting that they do not just send the stereotypical type of racism. The racism in this movie is coming from all sides. Racism is really like that in our society. It is not just whites hating blacks any more. It is affecting Asians, Hispanics, Blacks and whites equally. Racism includes all cultures no matter who would like to deny it. The message in this film is very clear.

Another European American woman from a community college in the Midwest aptly summarized a similar view: "People of all ethnicities can be both victims and abusers of racial discrimination, and most of them are represented in Crash." This observation was something that many other European Americans took away from the movie, including one who made the following point:

One thing I realized while watching Crash that I had never really considered before was the racial biases and prejudices minority groups impose on other minorities. I had always thought of minorities as victims, but this film exposed the reality that they can also be the offenders.

These and other similar comments not only individualize and de-institutionalize racism but also encourage essentialization of negative similarities with no recognition of larger power issues. Negative similarities are seen as unchanging, omnipresent, and beyond our control, and the source for viewing dominance and marginality as dynamic states (McPhail, 1996b). As a student from a Midwestern university shared:

I believe that there is just so much fear and hatred in the world that it is too late to turn back. There is never going to be peace, love, and harmony amongst all people. I think that is what was the worst part for me. That at the end of the day, people will always be people and there is always going to be someone that hates another for no reason. 
For this group of students, then, Crash showed that interracial relations could never improve. Instead of facilitating harmonic discourse (McPhail, 1994a,b), negative similarities in the form of coherence may help to justify people's withdrawal from participating in such a discourse.

As shown, our thematic analysis revealed multiple ways in which student responses to Crash spoke to the notions of complicity, coherence, and implicature. The responses displayed complicity by defining race relations as perpetually antagonistic. However, there were interesting differences as regards what the authors did with this observation; some students appeared to suggest hopelessness and thus disengagement from interracial problems, whereas other students took the dividedness as the very reason for engaging the problems. The analysis further demonstrated that complicity is also maintained by white blindness to, and denial of, the extent to which race historically matters to the personal and institutional lives of people of color (McPhail, 2004).

Coherence was invoked when the commonalities and interconnectedness of humanity were highlighted. The student responses referenced shared human experiences, morality, and emotions and stressed the influence we have on others' lives. Those similarities and implicature served as reasons for engaging others with compassion, and thus dialogic coherence (McPhail, 1996b). Coherence, however, was not simply about embraceable similarities but also about undesirable ones (e.g., we are all racist). Just as negative differences were reported, so negative similarities were also described by students. Some see this as a signal for self-examination, a step toward coherence, while others understand it as a sign that efforts toward coherence are useless. In this regard implicature, although a powerful, overarching message in Crash, did not always kindle the movement toward coherence. For implicature to serve as a transformative medium, we suggest that it needs to occur in conjunction with explicit historicization of race relations.

\section{Conclusion}

At the heart of complicity theory is the idea that race relations cannot improve unless coherence replaces complicity as the norm (McPhail, 1998a). In our critical thematic analysis of Crash, we sought to use multiple methods to explore the ways in which the characters in the film negotiated complicity and coherence, as well as how audience members became implicated within the film's plot. We have revealed complex readings of this much-discussed media text, and, by doing so, provide significant insight into the inherent value of complicity theory as a critical media analytic framework (e.g., Jackson, 2006). We conclude our analysis by describing several points of reflexivity that speak to the need for continued critical analysis of media texts focusing on race.

Based on our study, it is clear that movement from complicity to coherence is far from a simplistic notion. While the Crash plot utilized coherence to establish a clearly definable path toward more productive race relations, our analysis of student reactions demonstrated that a film's ability to mediate complicity in everyday life is a challenge. Student reactions revealed that explicit forms of complicity could actually serve as a motivation toward coherence; however, leaving complicity totally behind appeared impossible given the salience of race. Additionally, aspects of coherence* most notably the recognition of negative similaritiescontinue to hinder the facilitation of productive race relations. For example, student perceptions grounded in coherence were problematic in that they failed to recognize the historical ways in which racism has been institutionalized in ways that benefit the majority. In this regard, focusing on similarities and interdependence falsely led people to believe in a "color-blind" society in which racial differences are irrelevant. This articulation was perhaps intensified by the lack of recognition of difference as good, complementary, and necessary - an important aspect of coherence (McPhail, 1996b, 1998a) that Crash chose not to champion in depicting race relations.

A central question remains: Can media texts function as a process of mediation for viewers whereby they experience a move from complicity to coherence? We remain skeptical about the possibility of one film accomplishing this goal. Additionally, we question whether complicity is even the most productive approach to effective race relations. It appears that, first, individuals must acknowledge the complicitous nature of 
race*something that might be facilitated through compelling media texts. The next move, however, might not be to coherence; instead it might be a transitional state whereby similarities and differences are seen not as negative, but as complementary. Alternatively, scholars might utilize a dialectical approach alongside complicity theory. Within this triangulated theoretical framework, one might argue: Given the implicature of the human experience, effective race relations are facilitated through a negotiation of the tension between complicity and coherence. Instead of replacing complicity with coherence, perhaps a more productive approach might be similar to that advocated by Martin and Nakayama (1999). Their dialectical approach to intercultural communication revolves around several tensions, most notably static-dynamic, differences-similarities, and privilege-disadvantage, that appear especially central to the main tenets of complicity theory as evidenced by viewers' interactions with Crash. Such an eclectic approach to theorizing the process through which the viewing audience engages different mass-mediated forms of racialized popular culture is necessary for a "coherent integration of similarity and difference" (McPhail, 1998a, p. 115); Jackson (2006) asserts such integration would facilitate "a more sophisticated, holistic, and revelatory understanding" (p. 110) of race in everyday life. Perhaps, at best, Crash and other contemporary race films can put on display the tensions inherent in our collective racial predicament and mediate a process by which viewers are faced with intense questions about self, other, and society. If critical media scholars take up these questions and provocatively explore them, we will continue to learn something new about how a film experience intervenes in our on-going negotiation with social/cultural life.

\section{Notes}

[1] Another film that explores race relations, with a plot grounded in implicature, is What's Cooking? (2000). Interestingly, the parallels between this film and Crash are noteworthy: both explore the dynamics of race and ethnicity (and related issues such as assimilation, identity, relationships, and gun violence) through a multicultural cast over a single day/day and a half around the Thanksgiving--Christmas holiday season.

[2] Several events in the movie imply that the European American DA and his African American assistant are romantically involved. When he receives the call from his wife, the DA and his assistant are about to enter an elevator together; after he answers the call, he enters the elevator alone.

[3] As the movie concludes, and the credits begin to appear, the Stereophonics' Maybe Tomorrow plays: "I've been down and wondering why; little black clouds; keep walking around; with me; with me; so maybe tomorrow; I'll find my way home; so maybe tomorrow; I'll find my way home.',

[4] "Driving While Black" refers to the practice of racial profiling, whereby "a person's race or ethnicity influences police decisions to stop citizens, search them, or make an arrest" (Barlow, 2001, p. 3).

[5]Of note, this heart-tugging scene ends as the locksmith's beeper goes off. In their written reactions, many white students describe how they immediately assumed that he was being called away not for a work-related reason, but to participate in some form of illegal activity.

[6] In an earlier scene, Daniel comforts his daughter who he finds sleeping under her bed in fear of being shot. Daniel explains that she doesn't have to worry about that happening again because they have moved into a safer neighborhood. When his daughter remains unconvinced, he gives her an invisible protective cloth that can stop bulletssomething that his mother gave to him as a child.

[7] There were 54 participants from the southeastern campus, 51 from the Midwestern university, and 31 from the Midwestern community college.

[8] As such, some (but not all) of the assignments asked students to describe their cultural identities within the context of their reactions to the film. While this provides some cultural context for the data, it only provides partial information regarding the demographic composition-in terms of race, ethnicity, gender, age, etc.-of the total participant population. When available, we make note of salient demographic descriptors that help to contextualize viewers' reactions.

\section{References}

Allen, B. J. (2007). Theorizing communication and race. Communication Monographs, 74, 259-264. Apker, J., Propp, K. M., \& Ford, W. S. Z. (2005). Negotiating status and identity tensions in healthcare team interactions: An exploration of nurse role dialectics. Journal of Applied Communication Research, 33, 92115. 
Atkinson, R. (2005). Agitation in the city of angels. Clinical Psychiatry News, 33(10), 20-21. Barlow, H. D. (2001). Driving While Black": Observations on the practice and future of racial profiling in the U.S. Journal of Intergroup Relations, 38(3), 316.

Bourgeois, H. (1992). Hollywood and the civil rights movement: The case of "Mississippi Burning". Howard Journal of Communications, 4, 157-163.

Bowers, D. L. (1994). Afrocentrism and Do the Right Thing. In B. Brummett (Ed.), Rhetoric in popular culture (pp. 199222). New York: St. Martin's Press.

Brummett, B. (1985). Electric literature as equipment of living: Haunted house films. Critical

Studies in Mass Communication, 2, 247-261.

Chidester, P., Campbell, S., \& Bell, J. (2006). Black is blak": Bamboozled and the crisis of a postmodern racial identity. Howard Journal of Communications, 17, 287-306.

Cunneen, J. (2006, March 31). Reaching across the boundaries: Multiracial 'Crash' didn't deserve its Oscar.

National Catholic Reporter, p. 14.

Cuomo, C. (1995). Spinsters in sensible shoes: Mary Poppins and Bedknobs and Broomsticks. In E. Bell, L.

Haas, \& L. Sells (Eds.), From mouse to mermaid: The politics offilm, gender, and

culture (pp. 212-223). Bloomington: Indiana University Press.

Dace, K. L., \& McPhail, M. L. (2002). Crossing the color line: From empathy to implicature in intercultural communication. In J. N. Martin, T. K. Nakayama, \& L. A. Flores (Eds.), Readings in cultural contexts (pp. $344-$ 350). Mountain View, CA: Mayfield.

Detweiler, C. (2005, December). Cultural collisions. Sojourners, 34(11), 45-46.

Fine, M. (1991). New voices in the workplace: Research directions in multicultural communication. The Journal of Business Communication, 28, 259275.

Gabriel, J. (1998). Whitewash: Racialized politics and the media. London: Routledge.

Giroux, H. A. (2002). Breaking in to the movies: Film and the cultural politics. Malden, MA: Blackwell.

Hatch, J. B. (2003). Reconciliation: Building a bridge from complicity to coherence in the rhetoric of race relations. Rhetoric and Public Affairs, 6, 737-764.

hooks, b. (1996). Reel to real: Race, sex, and class in the movies. New York: Routledge.

Jackson, R. L. (2000). So real illusions of black intellectualism: Exploring race, roles, and gender in the academy. Communication Theory, 10, 4863.

Jackson, R. L. (2006). Scripting the black masculine body: Identity, discourse, and racial politics in popular media. Albany: State University of New York Press.

Kermode, M. (2005, August 15). Grace riot: An LA parable finds a spiritual dimension in earthly ructions. New Statesman, p. 33.

Kotler, S. (2005, November 16). Crash. Daily Variety, p. 13.

Madison, D. S. (1995). Pretty Woman through the triple lens of black feminist spectatorship. In E. Bell, L.

Haas, \& L. Sells (Eds.), From mouse to mermaid: The politics offilm, gender, and culture (pp. 224235).

Bloomington: Indiana University Press.

Madison, K. (1999). Legitimation crisis and containment: The "anti-racist-white-hero" film. Critical Studies in Mass Communication, 16, 399-416.

Martin, J.N., \& Nakayama, T. (1999). Thinking dialectically about culture and communication. Communication Theory, 9,1-25.

Matthews, M.R. (2005/2006). "You think you know who you are ... You have no idea'? Critical reflections on the movie Crash. Journal of Intergroup Relations, 32, 96-101.

McCormick, M. (2005). Crash movie review. U.S Catholic, 70(10), 46.

McPhail, M. L. (1991). Complicity: The theory of negative difference. Howard Journal of

Communications, 3, 1-13.

McPhail, M. L. (1994a). The rhetoric of racism. Lanham, MD: University Press of America. McPhail, M. L. (1994b). The politics of complicity: Second thoughts about social construction of

racial equality. Quarterly Journal of Speech, 80, 343-357,

McPhail, M. L. (1996a). Race and sex in black and white: Essence and ideology in the Spike Lee discourse.

Howard Journal of Communications, 7, 127-138. 
McPhail, M. L. (1996b). Zen in the art of rhetoric: In inquiry into coherence. Albany: State University of New York Press.

McPhail, M. L. (1998a). From complicity to coherence: Rereading the rhetoric of Afrocentricity. Western Journal of Communication, 62, 114-140.

McPhail, M. L. (1998b). Passionate intensity: Louis Farrakhan and the fallacies of racial reasoning. Quarterly Journal of Speech, 84, 416-429.

McPhail, M. L. (2002). The rhetoric of racism revisited: Reparations of separation?. Lanham, MD: University Press of America.

McPhail, M. L. (2004). A question of character: Re(-)signing the racial contract. Rhetoric and Public Affairs, 7, 391-405.

Miller, S., \& Rode, G. (1995). The movie you see, the movie you don't: How Disney does that old time derision. In E. Bell, L. Haas, \& L. Sells (Eds.), From mouse to mermaid: The politics of film, gender, and culture (pp. 86-103). Bloomington: Indiana University Press.

Owen, W. (1984). Interpretive themes in relational communication. Quarterly Journal of Speech, 70, 274-287, Patton, C. (1995). White racism/black signs: Censorship and images of race relations. Journal of Communication, 45, 6577,

Patton, T. O. (2004). In the guise of civility: The complicitous maintenance of inferential forms of sexism and racism in higher education. Women's Studies in Communication, 27, 60-87,

Rowland, R. C., \& Strain, R. (1994). Social function, polysemy and narrative-dramatic form: A case study of "Do the Right Thing'. Communication Quarterly, 42, 213-228.

Rozen, L. (2005, May 16). Crash: Sandra Bullock, Don Cheadle, Matt Dillon, Terrence Howard, Thandie Newton, Brendan Fraser. People Weekly, p. 39.

Schwarzbaum, L. (2005, May 13). Crash: A stellar multicultural cast takes a collision course. Entertainment Weekly, p. 65.

Sicinski, M. (2005). Crash. Cineaste, 30(4), 5152.

Thompson, A. (2005, September 16). Haggis' new career: Million-dollar writer. Hollywood Reporter, pp. 6-7, Watts, E. K., \& Orbe, M. (2002). The spectacular consumption of "true" African American culture: "Whassup" with the Budweiser guys? Critical Studies in Media Communication, 19, 120.

Wright, T. J., \& Orbe, M. (2003). Turning the tables of analysis in intercultural communication research: Studying the facework strategies used by "anonymous" European American reviewers. Howard Journal of Communications, 14, 1-15.

Young, S. D. (2000). Movies as equipment for living: A development analysis of the importance of film in everyday life. Critical Studies in Mass Communication, 17, 447458. 